PACS 78.47.+p, 78.55.A, 7867.Bf

\title{
Zn and Mn impurity effect on electron and luminescent properties of porous silicon
}

\author{
V.E. Primachenko, S.I. Kirillova, E.G. Manoilov, I.M. Kizyak, \\ B.M. Bulakh, V.A. Chernobai and E.F. Venger \\ V. Lashkaryov Institute of Semiconductor Physics, NAS of Ukraine, \\ 45, prospect Nauky, 03028 Kyiv, Ukraine \\ E-mail:pve18@isp.kiev.ua
}

\begin{abstract}
Investigated in this work are por-Si $/ n-\mathrm{Si}$ structures prepared by anodizing silicon in $1 \% \mathrm{HF}$ water solution, which was followed by natural aging in air and doping with $\mathrm{Zn}$ and $\mathrm{Mn}$ impurities. When aging, the oxide film of nanoelements in the above structures is substituted by a silicate one. Measurements of temperature dependencies $(100 \ldots 300 \mathrm{~K})$ describing the capacitance photovoltage behavior caused by intense pulses $\left(\sim 10^{21}\right.$ quanta/ $\left./ \mathrm{cm}^{2} \mathrm{~s}\right)$ of red or white light enabled us to determine the following values and their changes: the boundary potential for $n$-Si, distribution of the concentration inherent to boundary electron states in the $n$-Si forbidden gap, concentration of traps for non-equilibrium holes at the interface por- $\mathrm{Si} / n-\mathrm{Si}$ and in the por-Si layer. The substitution of the oxide film by the silicate one, the thickness of which can exceed the initial thickness of the oxide film, makes these structures more stable and results in sizable changes of spectral dependencies of the short-time $(t<250 \mathrm{~ns})$ and integrated $(t>250 \mathrm{~ns})$ photoluminescence relaxation components as well as shifts the latter into the shortwave range.
\end{abstract}

Keywords: porous silicon, capacitance photovoltage, photoluminescence, doping metal, boundary electron states, electron traps.

Manuscript received 22.06.05; accepted for publication 25.10.05.

\section{Introduction}

In the cycle of works [1-7] that were summarized in the monograph [8], we revealed multilayer adsorption of metal ions possessing negative electrochemical (standard) potential (Zn, Mn, In, Sb, Al, Ni, Co, Cr, Fe) from water solutions onto real surfaces of silicon and germanium. The multilayer adsorption phenomenon is as follows. It is known $[9,10]$ that a real surface of germanium or silicon is covered with an oxide film that in water solutions, especially containing acid or alkali, is solved passing into these solutions as compounds of $\mathrm{Ge}$ or Si. When salts of metals with the negative electrochemical potential are introduced into these solutions, one can observe joint self-organized adsorption of the solved oxide elements and ions of the introduced metals onto the surface of semiconductors, which is followed by creation of multilayer germanate or silicate films, respectively.

This phenomenon can be successfully used in silicon or germanium nanotechnology when silicon (germanium) nanoparticles usually covered with the oxide film can be very simply covered with the respective silicate (germanate) film instead of the oxide one. It opens a wide way to new application of silicon (germanium) nanostructures in various applied fields, in particular: heterogeneous catalysis, creation of various sensors and electroluminescent devices based on nanostructures, etc. In this case, we deal with the nanoparticles of single material (germanium or silicon), the coating of which is simply varied with different materials (germanate, silicate) possessing variable properties. Moreover, choosing the necessary conditions of preparing and doping these nanostructures, one can create nanoparticles of various sizes, which can considerably change their variable properties [11]. Note that according to [12] the similar broad application can be found for nanocrystalline (porous) structures doped with metal impurities possessing the positive electrochemical potential ( $\mathrm{Au}, \mathrm{Ag}, \mathrm{Cu}, \mathrm{Pd}, \mathrm{Pt}$, and so on), when nanocrystals of these metals are formed inside this nanocrystalline matrix.

In this work, we studied porous silicon as an example of a nanocrystalline structure. To dope it, we used $\mathrm{Zn}$ and $\mathrm{Mn}$ salts $\left(\mathrm{ZnCl}_{2}, \mathrm{MnCl}_{2}\right)$. It allowed to create silicate shells around silicon nanocrystals. Using these specific examples, we have shown how can electron and luminescent properties of porous silicon films located on the single-crystalline silicon substrate be changed. 


\section{Experimental}

Porous silicon layers with the thickness $1.0 \mu \mathrm{m}$ were prepared on the large $\langle 111\rangle$ face of $n$-type silicon samples possessing the resistivity $40 \mathrm{Ohm} \mathrm{cm}$ and sizes $1.5 \times 0.5 \times 0.05 \mathrm{~cm}$. To prepare por-Si, we used the method offered in [13] for manufacturing electroluminescent diodes based on this material, namely: the samples were anodized in $1 \% \mathrm{HF}$ water solution under the current density $4 \mathrm{~mA} / \mathrm{cm}^{2}$ for $5 \mathrm{~min}$ illuminating the anodized surface with an incandescent filament lamp of $P=100 \mathrm{~W}$ power. After preliminary elimination of the por-Si layer at the ends of the obtained samples por-Si $/ n$ $\mathrm{Si}$, we burnt in the ohmic $\mathrm{Au}\langle\mathrm{Sb}\rangle$ contacts. Then, the contacts with their wire leads were covered with a chemically stable dope. Measurements of the capacitance photovoltage temperature dependencies and the time-resolved photoluminescence spectral ones were made before and after doping the por-Si $/ n-\mathrm{Si}$ samples with impurities of electronegative metals by dipping them for definite time into $2 \cdot 10^{-2} \mathrm{M}$ water solutions of $\mathrm{ZnCl}_{2}$ or $\mathrm{MnCl}_{2}$ salts. In the course of the doping, metal ions penetrate into the por-Si layer [14] reaching the por$\mathrm{Si} / n$-Si boundary (it is confirmed by our photovoltage measurements). Besides, as it follows from our photoluminescence measurements, the doping time is sufficient for por-Si nanocrystals to be covered with a silicate coating. After doping procedure, the samples were dried with blotting paper and light heating with an incandescent filament lamp. Then, using these samples we performed the same measurements of the photovoltage and observed photoluminescence as before doping.

To measure the photovoltage in the cryostat providing the vacuum level approximately $10^{-4} \mathrm{~Pa}$ within the temperature range $100 \ldots 300 \mathrm{~K}$, we mounted the measuring capacitor consisting of the sample and a sheet of mica with deposited semi-transparent conducting electrode $\mathrm{SnO}_{2}\langle\mathrm{Sb}\rangle$ (mica surface without $\mathrm{SnO}_{2}$ being in contact with the por-Si layer). The specific capacitance of this capacitor was close to $100 \mathrm{pF} / \mathrm{cm}^{2}$. The electric signal from the capacitor caused by illuminating the latter with light pulses from the flash-lamp ИСШ-100 (pulse duration $\sim 10 \mu \mathrm{s}$, light flux $\approx 10^{21}$ quanta/ $/ \mathrm{cm}^{2} \mathrm{~s}$ ) was used as an input to the storage oscillograph C8-13. To determine the photovoltage signal value $V_{\mathrm{ph}}$, we performed calibration of the measuring scheme by using the testing electrical voltage. The intensity of the light pulse was sufficient to flatten silicon energy bands at the boundary with por-Si, therefore the measured $V_{\text {ph }}$ value taken from the $\mathrm{SnO}_{2}$ electrode in red light (that is not practically absorbed in the por-Si layer) was equal to the silicon boundary potential $V_{\mathrm{ph}}=-\varphi_{s}$ with the opposite sign. Note that the Dember photovoltage does not play an essential role as well owing to equalization of electron and hole mobilities in silicon under high levels of their generation [15].

$V_{\mathrm{ph}}$ temperature dependencies were measured in the course of cooling the samples in dark when slowing the temperature from 300 down to $100 \mathrm{~K}$ for 2 to 3 hours. In most cases when the temperature is lowered, it was essentially important to determine the $V_{\text {ph }}$ value during the first light pulse of the pulse train where they followed with $1 \mathrm{~Hz}$ frequency. It is associated with the fact that at lowered temperatures the light action causes trapping the generated minor charge carriers (holes) by traps located both at the boundary interface por-Si $/ n-\mathrm{Si}$ and inside the por-Si layer. This trapping changes the $V_{\mathrm{ph}}$ value determined under the second light pulse. Therefore, after measuring these $V_{\mathrm{ph}}^{(1)}$ and $V_{\mathrm{ph}}^{(2)}$ values, at the definite low temperature we heated the sample up to the temperatures when $V^{(1)}{ }_{p h}=V^{(2)}$ ph for emptying the traps from trapped holes. Then the sample was cooled down to lower temperatures, at which new $V^{(1)}$ ph and $V^{(2)}$ ph values were determined, etc. Note that the equality $V^{(2)}{ }_{p h}=V^{(3)}{ }_{p h}=V^{(4)}{ }_{p h}=\ldots$ was always valid, which is indicative that the first pulse duration is sufficient to saturate traps with holes. To determine the $n$-Si substrate boundary potential $\varphi_{s}$ and trapping the holes by the boundary interface traps, we measured the photovoltage in red light (by using the light filter $\mathrm{KC}-19$ transmitting the light within the range $700 \ldots 2700 \mathrm{~nm}$ ), while studying the process of hole trapping in the por-Si layer we used the unfiltered light of the flash-lamp ИСШ-100.

Excitation of the photoluminescence intensity $I_{\mathrm{PL}}$ was provided with the nitrogen laser radiation $(\lambda=337 \mathrm{~nm}$, $\left.\tau_{\text {pulse }}=8 \mathrm{~ns}, P_{\text {pulse }}=2 \mathrm{~kW}\right)$. Stroboscopic registration of the $I_{\mathrm{PL}}$ signal was carried out in the photon counting mode. The measuring strobe duration necessary to accumulate photons was $250 \mathrm{~ns}$. This work is illustrated with photoluminescence spectral dependencies obtained in the first strobe $(t \leq 250 \mathrm{~ns})$ after its excitation as well as integrated spectral dependencies obtained in the course of its relaxation for $t \geq 250 \mathrm{~ns}$ up to the full decay. Also, in some cases we determined the photoluminescence relaxation time.

\section{Experimental results and discussion}

The por-Si $/ n$-Si sample batch was made within one day. Then, we studied one of the non-doped por-Si $/ n-\mathrm{Si}$ structures, which was followed by doping it with metal and repeated investigations. After that, we took the second sample, the third one, etc. In this manner, studying the non-doped samples at definite time intervals after their preparation we investigated the aging effect for these por-Si $/ n$-Si structures, their stability. At the same time, by doping the differently aged samples we determined the doping influence on these structures for various initial levels of oxidizing the silicon nanocrystals in por-Si.

Depicted in Figs $1 \mathrm{a}$ and $1 \mathrm{~b}$ are photovoltage temperature dependencies $V_{\mathrm{ph}}(T)$ for the por-Si $/ n-\mathrm{Si}$ structures previously aged for 5 and 15 days, respectively, and then doped from $2 \cdot 10^{-2} \mathrm{M} \mathrm{ZnCl}_{2}$ water solution for 2 and 18 hours. Fig. 2 shows $V_{\mathrm{ph}}(T)$ dependencies for the same por-Si $/ n-\mathrm{Si}$ structure 

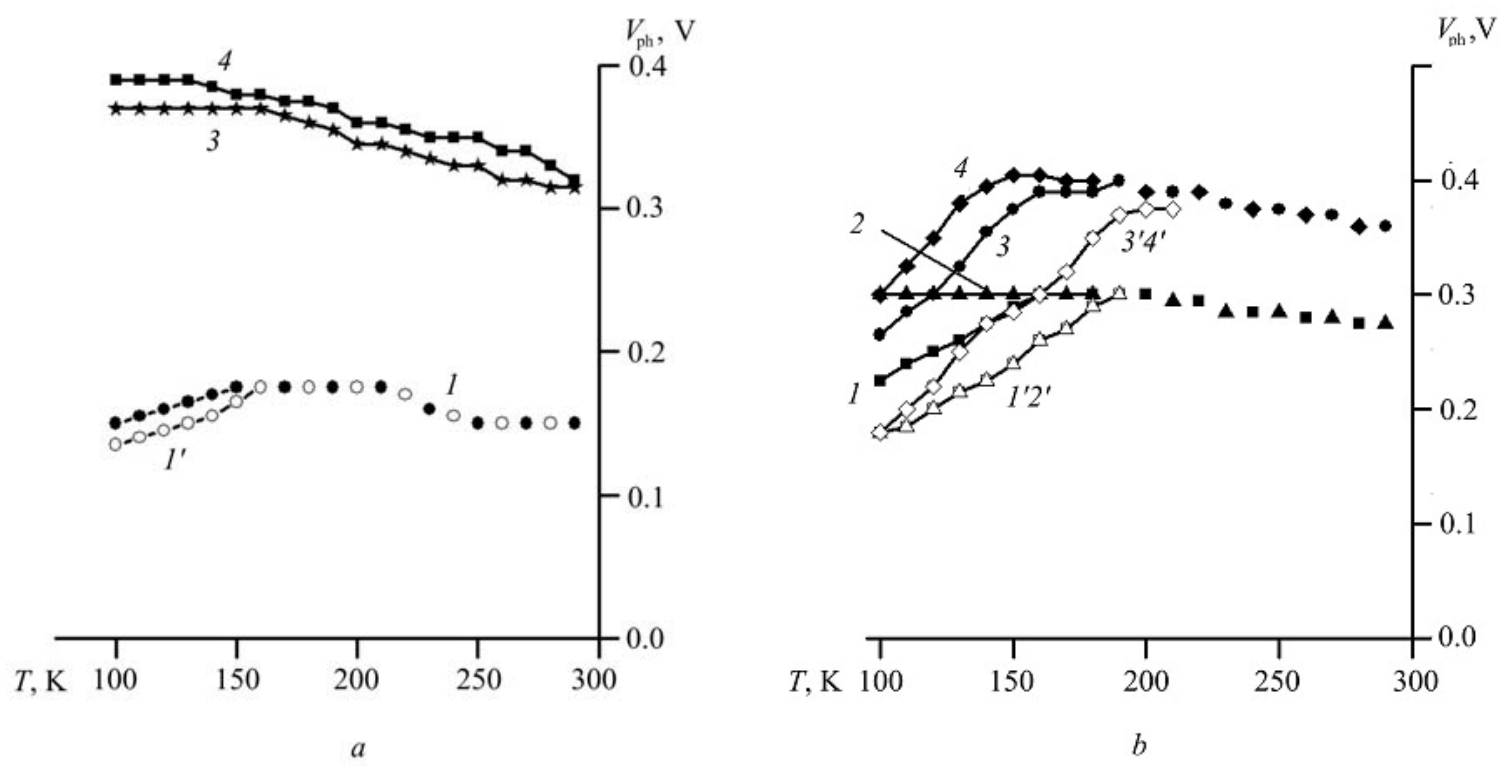

Fig. 1. Temperature dependencies of the capacitance photovoltage $V_{\mathrm{ph}}$ in the non-doped $\left(1,1^{\prime}, 2,2^{\prime}\right)$ and doped with $\mathrm{Zn}\left(3,3^{\prime}\right.$, $\left.4,4^{\prime}\right)$ por-Si $/ n$-Si structures, a and $\mathrm{b}$ - for the samples preliminary aged for 5 and 15 days, respectively.

$1,2,3,4$ denote the values obtained at the first pulses of red $(1,3)$ and white $(2,4)$ light; $1^{\prime}, 2^{\prime}, 3^{\prime}, 4^{\prime}$ denote the values obtained at the second pulses of red $\left(1^{\prime}, 3^{\prime}\right)$ and white $\left(2^{\prime}, 4^{\prime}\right)$ light.

preliminary aged for 160 days and then doped from $2 \cdot 10^{-2} \mathrm{M} \mathrm{MnCl}_{2}$ water solution for 24 hours. In the most of cases, these $V_{\mathrm{ph}}(\mathrm{T})$ dependencies were measured using red and white light to separate phenomena inside the bulk $n$-Si and at its surface as well as in the por-Si layer where absorption of the white light component with shorter wavelengths takes place. At lowered temperatures, in all the non-doped structures we observed the photomemory phenomenon caused by trapping the holes by traps located at the boundary interface por- $\mathrm{Si} / n-\mathrm{Si}$ as well as in por-Si, which is shown in the figures by respective dependencies with a dash. Besides, at low temperatures in all the non-doped structures we observed (to a variable degree) redistributing the system of boundary electron states (BES). This re-distribution was pronounced in decreased $V_{\mathrm{ph}}$ values with lowering the temperature and is associated with reversible structural transformations at the por-Si $/ n-\mathrm{Si}$ interface, which is typical for relatively unstable boundaries monocrystalline substrate - surface film with changing the temperature $[16,17]$. Also typical for these non-doped structures was slow gradual photocharging the traps in por-Si by holes after prolonged action of the light pulse train (approximately 100 pulses of white light) as opposite to fast charging the traps during the first pulse.

As seen from Figs 1 and 2, the non-doped structures are rather unstable, and $V_{\mathrm{ph}}$ values are considerably increased when aging the samples (keeping them in air). For example, at approximately $300 \mathrm{~K} V_{\mathrm{ph}}=-\varphi_{s}$ change from 0.15 up to $0.45 \mathrm{~V}$, which corresponds to the growing energy band bend up from 0.15 to $0.45 \mathrm{eV}$ in $n$ Si substrate. In this case, the $n$-Si Fermi level position at the boundary is changed from +0.08 down to $-0.21 \mathrm{eV}$ relatively to the middle of the silicon forbidden gap $E_{i}$.

When the temperature goes from 300 down to $100 \mathrm{~K}$, the Fermi level grows up from $E_{i}$, while BES are filled with electrons. In accord with [18], it enables to

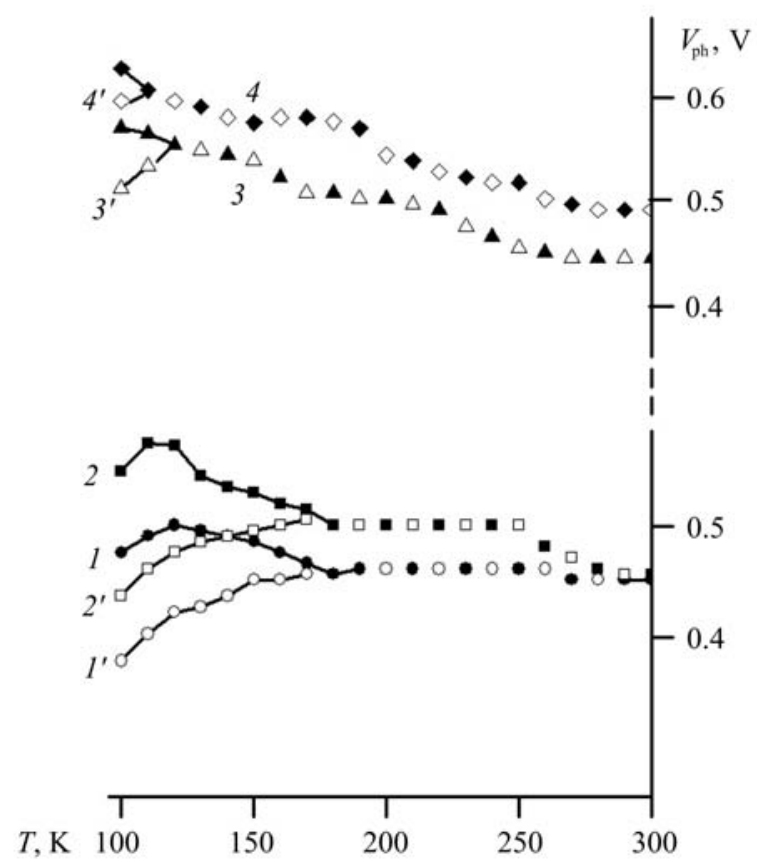

Fig. 2. Temperature dependencies of the capacitance photovoltage $V_{\mathrm{ph}}$ in the non-doped $\left(1,1^{\prime}, 2,2^{\prime}\right)$ and doped with $\mathrm{Mn}(3,4)$ structures preliminary aged for 160 days.1, 2, 3,4 denote the values obtained at the first pulses of red $(1,3)$ and white $(2,4)$ light; $1^{\prime}, 2^{\prime}, 3^{\prime}, 4^{\prime}$ denote the values obtained at the second pulses of red $\left(1^{\prime}, 3^{\prime}\right)$ and white $\left(2^{\prime}, 4^{\prime}\right)$ light. 


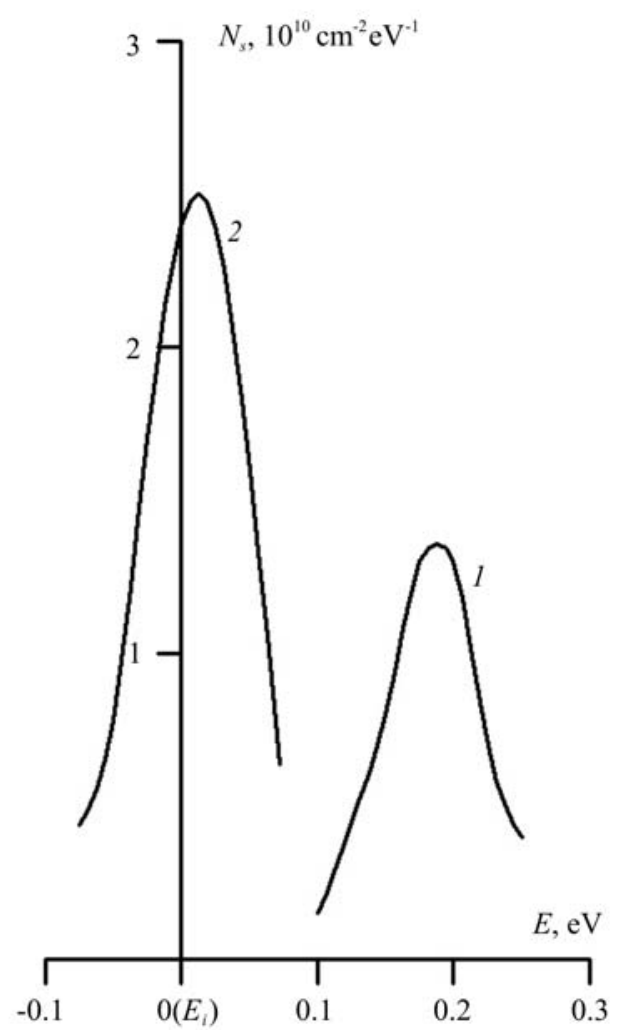

Fig. 3. Distribution of BES inside the forbidden gap $E_{g}$ of the aged for 5 days (1) and then doped with $\mathrm{Zn}(2)$ por-Si $/ n-\mathrm{Si}$ structure.

calculate the concentration of BES and its energy distribution in the definite part of the forbidden band. As the initial position of the Fermi level (at $300 \mathrm{~K}$ ) depends on the aging stage, then the change of the temperature from 300 down to $100 \mathrm{~K}$ in variously aged samples allows to study different parts of the forbidden gap. The curves 1 in Figs 3, 4 and 5 represent the energy distribution of the BES concentration $N_{s}$ within the forbidden gap relatively to $E_{i}$. It is seen that the sample aged for 5 days possesses the $N_{\mathrm{s}}(E)$ distribution within the range $+0.10 \ldots+0.25 \mathrm{eV}$ (above $E_{i}$ ), then that aged for 15 days within the range $-0.05 \ldots+0.10 \mathrm{eV}$, and that aged for 160 days - within the range $-0.20 \ldots 0 \mathrm{eV}$ (below $E_{i}$ ). The maximum concentrations in these distributions are equal, respectively, $\quad 1.35 \cdot 10^{10} \mathrm{~cm}^{-2} \mathrm{eV}^{-1}, \quad 1.30 \cdot 10^{10} \mathrm{~cm}^{-2} \mathrm{eV}^{-1}$, $1.70 \cdot 10^{10} \mathrm{~cm}^{-2} \mathrm{eV}^{-1}$, i.e., these are changed insignificantly when aging the samples. It is worth to note that the $N_{\mathrm{s}}$ value drop in the $N_{\mathrm{s}}(E)$ distributions in the field of high $E$ (right) can be caused by transformations in the BES system as a whole and cannot be responsible for the true character of the BES distribution in this area.

As seen from Figs 1 and 2, the growth of $V_{\text {ph }}$ value is observed when doping the structures with $\mathrm{Zn}$ and $\mathrm{Mn}$ (it is especially pronounced after Zn-doping the weakly aged structures). Besides, doping the structure aged for only 5 days with $\mathrm{Zn}$ resulted also in disappearance of photomemory and photocharging phenomena (Fig. 1a), i.e., in vanishing the traps for holes both at the por- $\mathrm{Si} / n$ $\mathrm{Si}$ boundary and in the por-Si layer. With lowering the temperature, transformation of the BES system in this structure is not practically observed, and the structure is weaker aged as compared to the non-doped one. It means it is more stable. All these changes in the sample after Zn-doping can be explained by the gradual substitution of the relatively thin oxide film covering silicon nanocrystals and some parts of the boundary por$\mathrm{Si} / n$-Si with a film of $\mathrm{Zn}$ silicate [8]. The small thickness of the oxide film provides its full dissolution that is followed by the $\mathrm{Zn}$-silicate film that does not contain traps for holes in contrast to the oxide film and is more stable as compared with the latter.

In the Zn-doped structure preliminary aged for 15 days, at lowered temperatures $(T \leq 200 \mathrm{~K})$ we observed the photomemory phenomenon and BES transformations as well as photocharging the por-Si layer with holes (Fig. 1b). Obviously, in this case the thicker oxide film with more dense structure [10] is formed on por-Si elements. It cannot be fully dissolved in water, especially at the boundary por-Si $/ n-\mathrm{Si}$. As a result, in the course of doping the silicon nanocrystals located closer to the external por-Si boundary acquire a silicate coating, while those being closer to the interface and in the oxidized parts of $n$-Si do not. It allows to explain the results of photovoltage measurements in this doped structure and the results of studying the photoluminescence behavior, which will be discussed below. This explanation of the results obtained is well agreed with the maximum $N_{\mathrm{s}}$ in the BES distribution for two Zn-doped structures (Figs 3

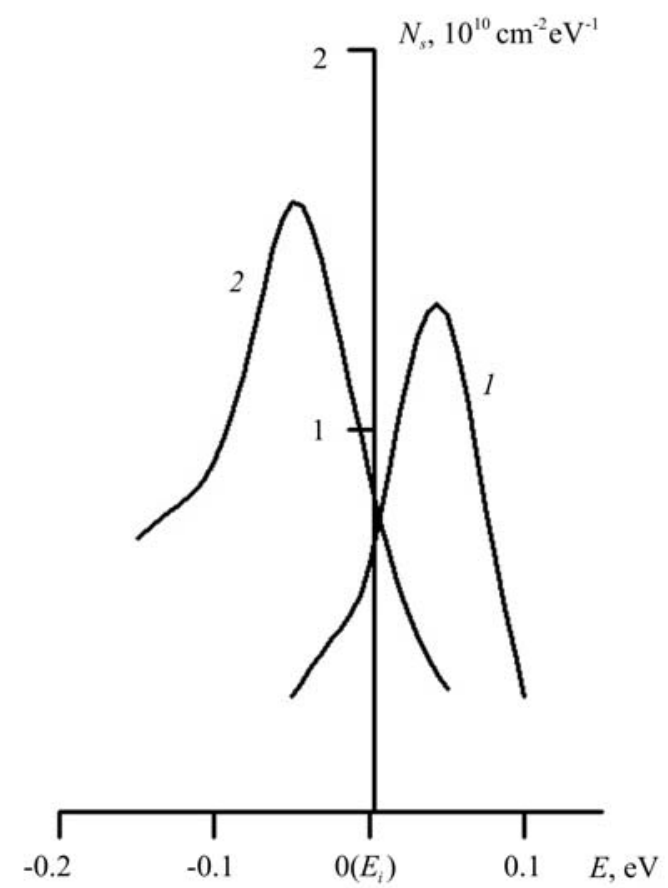

Fig. 4. Distribution of BES inside the forbidden gap $E_{g}$ of the aged for 15 days (1) and then doped with $\mathrm{Zn}(2)$ por-Si/n-Si structure. 
and 4, curves 2). When doping the weakly aged structure with $\mathrm{Zn}, N_{s}^{(\max )}$ grows in fact doubly (Fig. 3), while in doing so for the more aged structure it provides only $23 \%$ growth (Fig. 4). It is associated with the fact that in the former case the oxidized parts of the $n$-Si substrate were fully substituted with silicate parts, while in the latter case it did not take place. Obviously, the BES density at the boundary silicate film $-n-\mathrm{Si}$ is higher than that at the boundary oxide film $-n$-Si due to worse structural conjugation between the silicate film and $n$-Si as compared to the oxide one.

Some interesting results were obtained due to doping the strongly aged por-Si $/ n$-Si structure with Mn (Figs 2 and 5). In this case, doping from $2 \cdot 10^{-2} \mathrm{M} \mathrm{MnCl}_{2}$ water solution was carried out for 24 hours. It enables, obviously, to almost fully change the oxide film on por$\mathrm{Si}$ and $n$-Si elements with the film of Mn-silicate. As seen from Fig. 2, the Mn-doped structure does not show the transformation in the BES system, and small photomemory is observed only at $110 \ldots 100 \mathrm{~K}$. In addition, in this structure we could not observe photocharging the por-Si layer with photoholes when illuminating it with the white light pulse train.

Thus, the traps for holes are practically absent in por$\mathrm{Si}$ with structural elements covered with the Mn-silicate film, which is similar to the case of full covering the

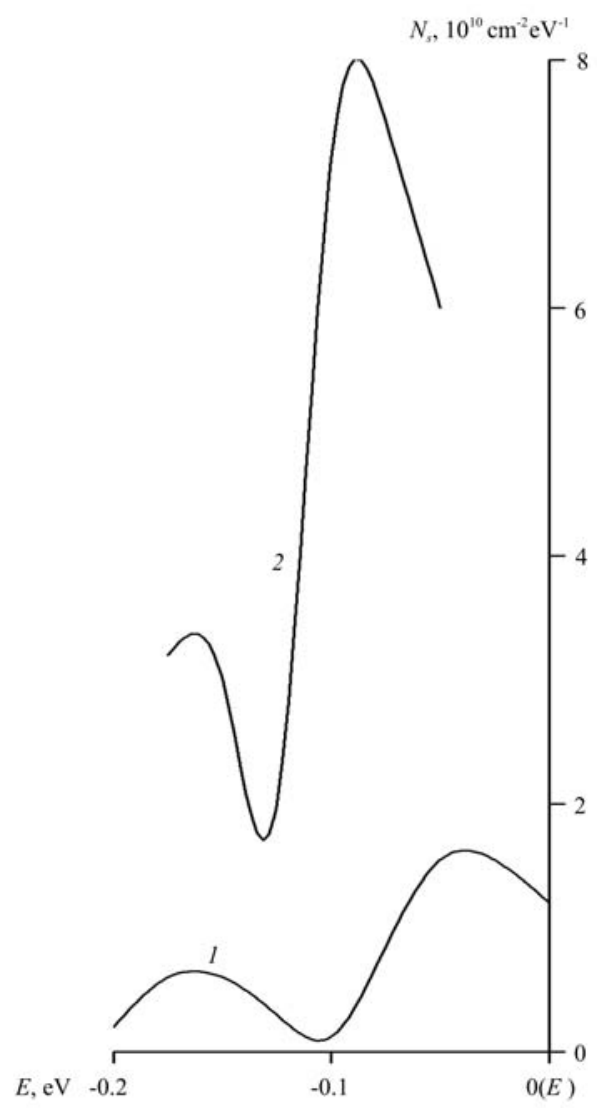

Fig. 5. Distribution of BES inside the forbidden gap $E_{g}$ of the aged for 160 days (1) and then doped with $\mathrm{Mn}(2)$ por-Si $/ n-\mathrm{Si}$ structure. elements with the $\mathrm{Zn}$-silicate film. Besides, the silicate films are harder connected with the silicon matrix. Therefore, the transformation of the BES system does not take place, as it is observed in the case of the amorphous $\mathrm{SiO}_{\mathrm{x}}$ film $(1<x<2)$. According to preliminary results, the por- $\mathrm{Si}\langle\mathrm{Zn}, \mathrm{Mn}\rangle / n-\mathrm{Si}$ structures are more stable in time than the por- $\mathrm{Si} / n-\mathrm{Si}$ ones. However, the silicate films probably have more point defects at the boundary with silicon than the oxide film has, which results in the higher BES concentration. It is well seen from Fig. 5 showing that the $N_{s}^{(\max )}$ value has the five-fold growth after doping the sample with $\mathrm{Mn}$.

As it was stated above, the lower $V_{\text {ph values obtained }}$ after the second light pulse are indicative of trapping the non-equilibrium holes by the $n$-Si boundary traps during the first red light pulse or total trapping the holes by boundary traps and those in the por-Si layer during the first white light pulse. Using the $V^{(\mathrm{r})}{ }_{\mathrm{ph}}(T)$ and $V_{\mathrm{ph}}^{(\mathrm{w})}(T)$ dependencies obtained with the first and second pulses of red and white light, one can calculate temperature dependencies of trapped hole amounts inherent both to the boundary traps and those in the por-Si film $N_{t}(T)$ and $N^{(\text {por })}(T)$, respectively. Figs 6 to 8 show these dependencies for non-doped samples as well as for the sample aged for 15 days and then doped with $\mathrm{Zn}$. As these traps were saturated with holes under the first light pulse action, the $N_{t}(T)$ and $N_{t}^{(\text {por })}(T)$ dependencies are simultaneously the temperature dependencies for concentrations of traps that trap the holes at the boundary and in the por-Si layer.

A non-monotonic behavior of the trap concentration with lowering the temperature, which is clearly seen from the curves depicted in Figs 6 to 8 , can be determined by two causes. First, by the trap distribution over the forbidden gap. With lowering the temperature, the deep traps (being closer to $E_{i}$ ) first of all trap and keep holes, since trapping the holes by traps more close to the $v$-band is accompanied by their reverse escape into the $v$-band. Therefore, the non-monotonic character of these dependencies can be related with availability at least two kinds of traps, namely: more deep and more shallow ones as regard to the $v$-band. Second, the nonmonotonic character of $N_{t}(T)$ and $N_{t}^{(\text {por })}(T)$ dependencies can be related with reversible structural transformations at the boundary por- $\mathrm{Si} / n-\mathrm{Si}$ as well as inside the por-Si films with decreasing the temperature. The structural transformations rebuilt not only the BES system but the systems of hole traps, in particular, their concentration distribution over the forbidden gaps at the boundary with $n$-Si as well as in the por-Si layer.

It is worth to note that, as it follows from Figs 6 to 8, the trap concentration for holes at the boundary increases and inside the por-Si layer is decreased in the course of aging the non-doped samples. In the most of cases, doping with $\mathrm{Zn}$ and $\mathrm{Mn}$ results in total elimination of traps for holes. In the case of the $\mathrm{Zn}$-doped sample aged for 15 days, the trap concentration inside the por-Si is 
approximately halved (Fig. 7), while that at the boundary with $n$-Si is even increased to some extent (Fig. 6).

Let us proceed to the results obtained when measuring photoluminescence in the samples both nondoped and doped with $\mathrm{Zn}$ and $\mathrm{Mn}$. It is noteworthy that the "aging effect" in photoluminescence was not studied in this work. In all the samples under study, the photoluminescence intensity $I_{\mathrm{PL}}$ decay in time can be conventionally separated by three time parts: i) in the first strobe $I^{(1)}{ }_{\mathrm{PL}}(t<250 \mathrm{~ns})$; ii) photoluminescence intensity $I_{\mathrm{PL}}^{(2)}$ decay by approximately an order of its magnitude for $30-40 \mu$ s (integrated component); iii) approximately $10 \%$ decay of the photoluminescence integrated value for the time $100-120 \mu$ s ("tail"). We did not observe any essential changes in decay times after doping. However, this procedure caused changes in the ratio $I_{\mathrm{PL}}^{(2)} / I_{\mathrm{PL}}^{(1)}$. While in the non-doped samples this ratio was of the order of 20, doping with $\mathrm{Zn}$ made this ratio decreased approximately by $25 \%$, and in doing so with $\mathrm{Mn}$ this ratio was decreased by $50 \%$. Thus, doping that is accompanied with a substitution of the oxide film covering silicon nanocrystals with the silicate one increases the fraction of the fast-time $I^{(1)}{ }_{\mathrm{PL}}$ component.

$\mathrm{Zn}$ - and Mn-doping also causes changes in the spectral distributions of photoluminescence in the first strobe $I^{(1)}{ }_{\mathrm{PL}}(h v)$ and of the integrated photoluminescence

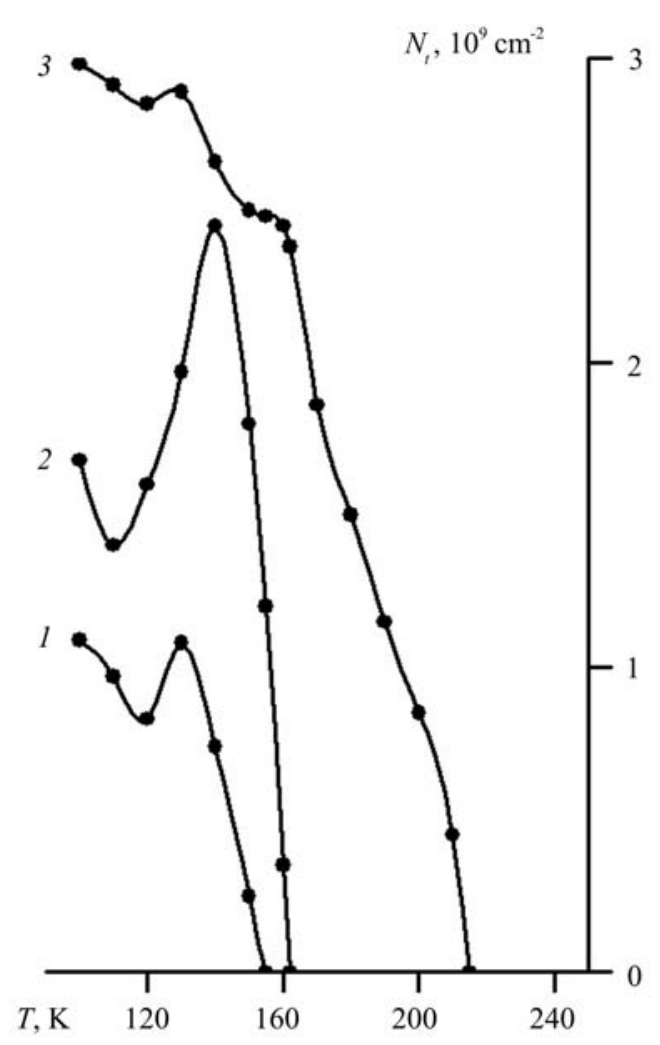

Fig. 6. Temperature dependencies for the concentration of traps $N_{t}$ trapping the holes in $n$-Si. 1 denotes the por-Si $/ n$-Si structure aged for 5 days, and 2, 3 denote the structure aged for 15 days and then doped with $\mathrm{Zn}$, respectively.
$I^{(2)}{ }_{\mathrm{PL}}(h v)$. Fig. 9 shows these spectral dependencies (in the reduced form $I_{\mathrm{PL}} / I_{\mathrm{PL}(\max )}$ ) for the samples both non-doped and doped with $\mathrm{Zn}\left(2 \cdot 10^{-2} \mathrm{M}, 18\right.$ hours $)$. When the sample was doped, we observed a shift in the $I^{(\max )}{ }_{\text {PL }}$ position from 1.97 up to $2.07 \mathrm{eV}$ within the first strobe (curves 1 and 2). The peak position of the integrated component has been shifted from 1.90 up to $2.00 \mathrm{eV}$ (curves 3 and 4). While the $I_{\mathrm{PL}}^{(2)}(h v)$ distributions for the non-doped and doped samples are symmetrical (and close to the Gaussians), after $\mathrm{Zn}$-doping, the $I^{(1)}{ }_{\mathrm{PL}}(h v)$ dependence becomes asymmetrical: one can observe a growth of the short-wave component $I_{\mathrm{PL}}^{(1)}$. It is clearly seen especially in Fig. 10 where the dependencies $I^{(1)}(h v)$ (curve 1) and $I_{\mathrm{PL}}^{(2)}(h v)$ (curve 2) are demonstrated for the sample doped with Mn.

The shortwave shoulder in the range 2.4 to $3.2 \mathrm{eV}$ (Fig. 10, curve 1) is a clear indication of the formation of a considerable number of smaller silicon nanocrystals (as compared with the non-doped structure), in which the electron-hole pair recombination takes place with radiation of shorter wavelengths owing to the wider forbidden gap. The reduction in the nanocrystal sizes during the doping procedure is associated with the supplementary oxidation of these nanocrystals and the following dissolution of both the initial and supplementary oxide films in the course of substituting them with the silicate film covering the nanocrystals [3].

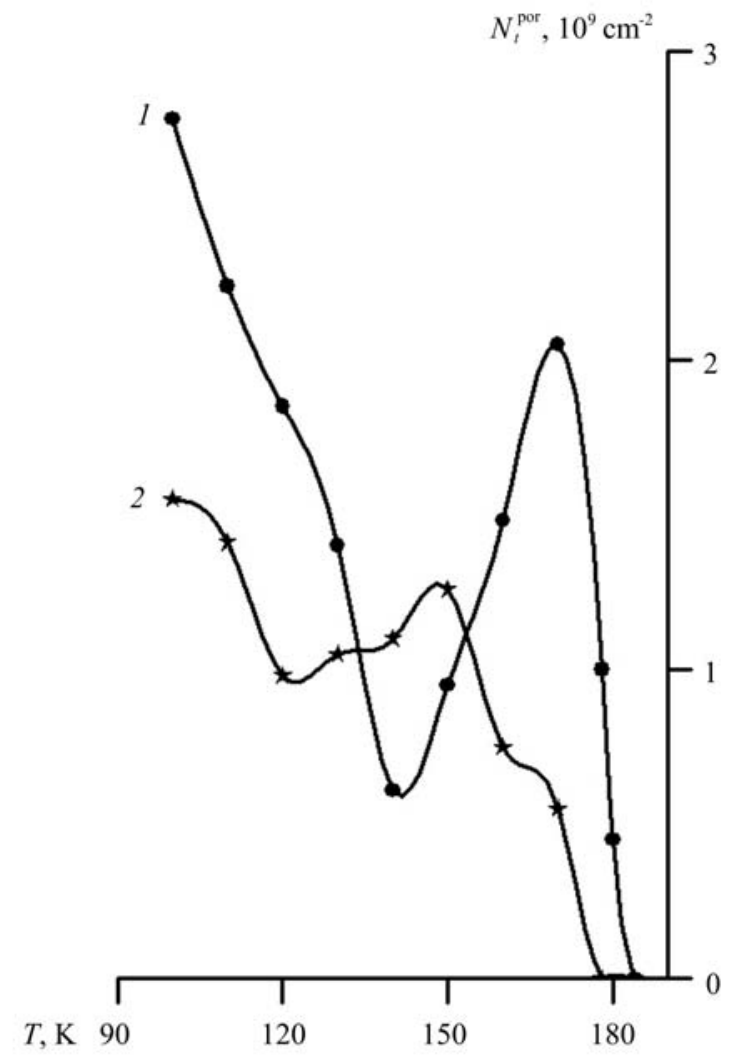

Fig. 7. Temperature dependencies for the concentration of traps $N_{t}^{\text {por }}$ trapping the holes in the por-Si layer. 1 and 2 stand for the structure preliminary aged for 15 days and then doped with $\mathrm{Zn}$, respectively. 


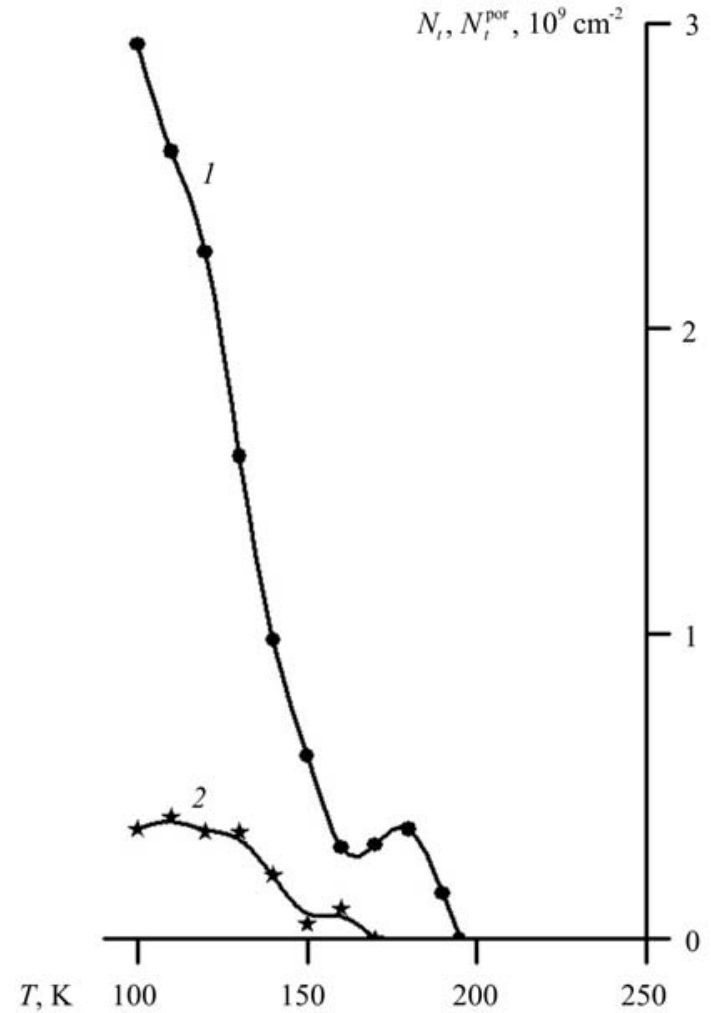

Fig. 8. Temperature dependencies for the concentration of hole traps in the structure preliminary aged for 160 days. 1 denotes the traps in $n$-Si, 2 - in por-Si.

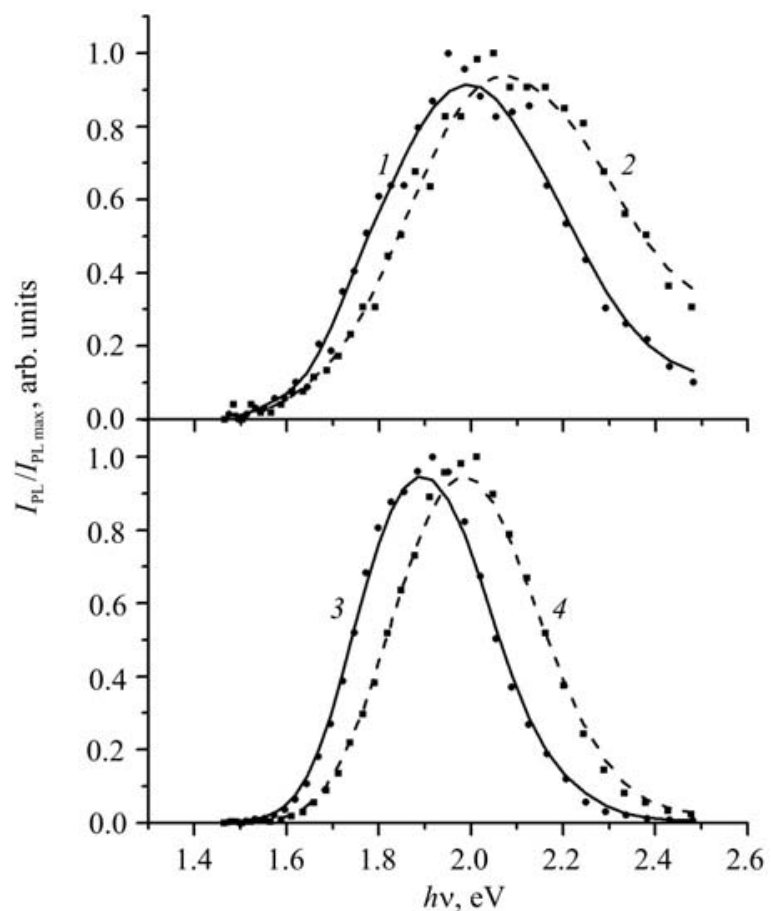

Fig. 9. Normalized photoluminescence spectral dependencies obtained within the first time $(t<250 \mathrm{~ns})$ strobe $(1,2)$ and within the integrated interval of $t>250 \mathrm{~ns}$ up to the full decay of photoluminescence $(3,4) .1,3$ denote the non-doped structure, while 2,4 - the structure doped with $\mathrm{Zn}\left(2 \cdot 10^{-2} \mathrm{M}\right.$, 18 hours).

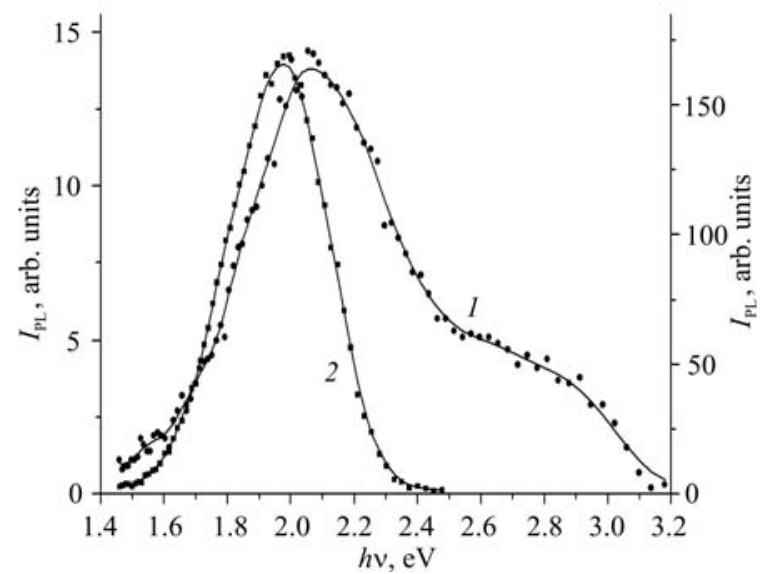

Fig. 10. Photoluminescence spectral dependencies obtained within the first strobe (curve 1) and integrated interval after the first strobe (curve 2 ) in the por-Si $/ n-\mathrm{Si}$ structure doped with $\mathrm{Mn}\left(2 \cdot 10^{-2} \mathrm{M}, 24\right.$ hours $)$ and preliminary aged for 160 days.

In such a manner, the silicon core of the nanocrystals is reduced, and the covering them silicate film possesses a larger thickness than that of the oxide film before doping.

In the papers [12, 19], the photoluminescence integrated component $I_{\mathrm{PL}}^{(2)}$ was explained by the radiative recombination of excitons related with $\mathrm{Si}=\mathrm{O}$ centers at the surface of silicon nanocrystal core. When changing the oxide film with the silicate one, these end $\mathrm{Si}=\mathrm{O}$ bonds can stay or create also at the boundary silicate film - silicon core. The proximity of the $I^{(2)}{ }_{\mathrm{PL}}(h v)$ integrated dependency look to the Gaussian after doping (as a contrast to $I^{(1)}{ }_{\mathrm{PL}}(h v)$ ) can serve as a confirmation of the fact that it is this process of recombination via $\mathrm{Si}=\mathrm{O}$ centers that takes place in all the nanocrystals despite their sizes. While the symmetrical shift of the $I_{\mathrm{PL}}^{(2)}(h v)$ dependencies into the shortwave range by 0.1 and $0.08 \mathrm{eV}$ after doping the samples with $\mathrm{Zn}$ and $\mathrm{Mn}$, respectively, can be explained by the weaker dependence of the $\mathrm{Si}=\mathrm{O}$ center energy position on the mean nanocrystal size [20] as compared to that for the forbidden gap width on the silicon nanocrystal core size.

\section{Conclusions}

1) The por- $\mathrm{Si} / n$-Si structures obtained by anodizing in $1 \%$ HF water solution are unstable when keeping them in the open air: we observed the increase of the $n$-Si boundary potential magnitude $\left|\varphi_{s}\right|$ (bend of the energy bands from 0.15 up to $0.44 \mathrm{eV}$ ) and growth of the hole trap concentration at the interface ( $N_{t}^{(\max )}$ changes from $1 \cdot 10^{9}$ up to $3 \cdot 10^{9} \mathrm{~cm}^{-2}$ ). Also, we observed some growth in the BES density (from $1.3 \cdot 10^{10}$ up to $1.7 \cdot 10^{10} \mathrm{~cm}^{-2} \mathrm{eV}^{-1}$ ) as well as the change in the hole trap concentration in the por-Si layer (from $2.8 \cdot 10^{9}$ до $0.4 \cdot 10^{9} \mathrm{~cm}^{-2}$ ). 
2) Doping the por- $\mathrm{Si} / n-\mathrm{Si}$ structures at various stages of aging them (5 to 160 days) with $\mathrm{Zn}$ and $\mathrm{Mn}$ impurities from water solutions $\left(2 \cdot 10^{-2} \mathrm{M}\right)$ of $\mathrm{ZnCl}_{2}$ and $\mathrm{MnCl}_{2}$ salts results in increasing the boundary potential $\left|\varphi_{s}\right|$ (especially sizable in the case of weakly aged structures) and in growth of the BES density $\left((1.6 \ldots 2.5) \cdot 10^{10} \mathrm{~cm}^{-2} \mathrm{eV}^{-1}\right.$ for $\mathrm{Zn}$, and $8 \cdot 10^{10} \mathrm{~cm}^{-2} \mathrm{eV}^{-1}$ for $\mathrm{Mn})$. When the oxide film covering the nanoelements in the por-Si structure is fully substituted with the silicate one, the hole traps vanish both in por-Si bulk and at the por-Si $/ n-\mathrm{Si}$ boundary, the white light pulse train cannot provide the photocharging effect in por-Si, and the transformation effect in the BES system is not observed with lowering the temperature from 300 down to $100 \mathrm{~K}$ as well. All the mentioned above is indicative of the more stable boundary between $n$-Si and the silicate film contrary to that between silicon and the oxide one.

3) $\mathrm{Zn}$ - and Mn-doping the por-Si $/ n-\mathrm{Si}$ structures, which weakly changes the total value of the photoluminescence intensity $I_{\mathrm{PL}}$ and relaxation times of its components, redistributes the values of photoluminescent fractions: the fraction of the fast $(t<250 \mathrm{~ns})$ relaxation component $I^{(1)}{ }_{\mathrm{PL}}$ grows as compared with that of the integrated one $\left(I^{(2)} \mathrm{PL}\right.$, $250 \mathrm{~ns}<t<120 \mu \mathrm{s})$. The $I^{(1)}{ }_{\mathrm{PL}}$ growth is associated with the increasing role of the geminate electron-hole recombination inside the silicon nanocrystal core when changing their oxide coating by the silicate one. While the decrease in the $I^{(2)}{ }_{\mathrm{PL}}$ value is conditioned by the less part of the excitons bound at $\mathrm{Si}=\mathrm{O}$ centers, which mainly determines the integrated part of the photoluminescence relaxation.

4) After Zn- and Mn-doping, the $I^{(1)}{ }_{\mathrm{PL}}(h v)$ and $I^{(2)}{ }_{\mathrm{PL}}(h v)$ spectral dependencies shift to the shortwave side. The $I_{\mathrm{PL}}^{(2)}(h v)$ spectrum before and after doping possesses the shape similar to the Gaussian, which indicates that the photoluminescence relaxation in this part is determined by $\mathrm{Si}=\mathrm{O}$ centers. At the same time, the $I^{(1)}{ }_{\mathrm{PL}}(h v)$ dependencies become strongly asymmetrical after doping their shortwave shoulder grows.

It is explained by the reduced core size in the considerable part of silicon nanocrystals due to creation of covering silicate films.

Simultaneously, it confirms the conclusion that the fast $I_{\text {PL }}^{(1)}$ component is determined by the electron-hole pair recombination in the silicon nanocrystal core, as the emitted quantum energy essentially depends on the silicon core size.

\section{References}

1. V.V. Milenin, V.Ye. Primachenko, V.G. Popov, O.V. Snitko, Investigation of electron properties of silicon surface doped with metals possessing the negative electrochemical potential // Fizika i tekhnika poluprovodnikov 13 (8), p.1532-1538 (1979) (in Russian).

2. V.V. Antoshchuk, V.Ye. Primachenko, O.V. Snitko, Spectroscopical study of silicon surface doped with zinc // Poverkhnost'. Fizika, khimiya, mekhanika No 8, p.167-168 (1982) (in Russian).

3. V.V. Milenin, V.Ye. Primachenko, N.A. Rastrenenko, O.V. Snitko, N.M. Torchun, Structural transformations on the real semiconductor surface under adsorption of ions of metals with the negative electrochemical potential // Izvestiya AN SSSR, ser. Neorganicheskiye materialy $\mathbf{1 8}(2), \quad$ p. 192-196 (1982) (in Russian).

4. S.I. Kirillova, V.Ye. Primachenko, O.V. Snitko, Relaxation of non-equilibrium depletion at silicon surface doped with zinc // Ukrainskiy fizicheskiy zhurnal 27 (8), p. 1181-1186 (1982) (in Russian).

5. V.M. Mayevskiy, V.Ye. Primachenko, O.V. Snitko, N.G. Frolova. Investigation of ESR centers on the real and doped with metals silicon surface // Poverkhnost'. Fizika, khimiya, mekhanika No 1, p. 101-105 (1983) (in Russian).

6. V.V. Antoshchuk, V.Ye. Primachenko, O.V. Snitko, Photoelectric properties of the doped with zinc silicon surface in the IR spectral range // Poverkhnost'. Fizika, khimiya, mekhanika No 10, p. 134-136 (1983) (in Russian).

7. V.V. Antoshchuk, V.Ye. Primachenko, O.V. Snitko, E.Ye. Petrosyan, Influence of $\mathrm{Ba}, \mathrm{Ca}, \mathrm{Zn}$ adsorption on the value and photomemory of the surface potential in germanium // Ukrainskiy fizicheskiy zhurnal 32(2), p. 281-284 (1987) (in Russian).

8. V.Ye. Primachenko, O.V. Snitko, Physics of the semiconductor surface doped with metals. Naukova dumka, Kiev (1988) (in Russian).

9. T.I. Kovalevskaya, K.K. Svitashev, Spectroscopic investigation of the real germanium surface structure // Fizika i tekhnika poluprovodnikov 3(6), p. 779-782 (1969) (in Russian).

10. V.V. Antoshchuk, V.Ye. Primachenko, O.V. Snitko, IR absorption spectra of the real silicon surface // Ukrainskiy fizicheskiy zhurnal 20(7), p. 1081-1084 (1975) (in Russian).

11. Nanosystems, nanomaterials, nanotechnologies. The collection of scientific papers. V. 1, No 2. Published by “Akademperiodika”, Kiev (2004) (in Russian).

12. V.Ye. Primachenko, Ya. F. Kononets, B.M. Bulakh, Ye.F. Venger, E.B. Kaganovich, I.M. Kizyak, S.I. Kirillova, E.G. Manoilov, Yu.A. Tsyrkunov, Electron and emission properties of porous silicon doped with gold // Fizika i tekhnika poluprovodnikov 39(5), p. 595-601(2005) (in Russian).

13. S.K. Lazaruk, P.V. Zhagiro, A.A. Leshok, V.Ye. Borisenko, Physical phenomena in avalanche photodiodes based on porous silicon // Izvestiya AN SSSR. Ser. fiz. 66(2), p. 179-182 (2002) (in Russian).

14. D. Andsager, J. Hilliard, J.M. Hetrick, L.H. AbuHassan, M. Plisch, M.H. Nayfeh, Quenching of porous silicon photoluminescence by deposition of 
metal adsorbates // J. Appl. Phys. 74(7), p. 47834785(1993).

15.Z.S. Gribnikov, V.I. Mel'nikov, Electron-hole scattering in semiconductors at high injection levels // Fizika i tekhnika poluprovodnikov 2(6), p. 1352-1360 (1968) (in Russian).

16. S.I. Kirillova, V.Ye. Primachenko, V.A. Chernobai, O.V. Snitko, Electron properties of silicon surface being in various physico-chemical states // Poverkhnost'. Fizika, khimiya, mekhanika No 11, p. $74-79$ (1991) (in Russian).

17. Ye.F. Venger, T.Ya. Gorbach, S.I. Kirillova, V.Ye. Primachenko, V.A. Chernobai, Changes in the system porous silicon on silicon in the course of gra- dual etching the por-Si layer // Fizika i tekhnika poluprovodnikov 36(3), p. 349-354 (2002) (in Russian).

18. S.I. Kirillova, V.E. Primachenko, E.F. Venger, V.A. Chernobai, Electronic properties of silicon surface at different oxide film conditions // Semiconductor Physics, Quantum Electronics and Optoelectronics 4(1), p.12-18 (2001).

19. Ye. F. Venger, S.I. Kirillova, I.M. Kizyak, E.G. Manoilov, V.E. Primachenko, Influence of the gold impurity on photoluminescence and photovoltage of porius silicon // Fizika i tekhnika poluprovodnikov 38(1), p. 117-123 (2004) (in Russian).

20. A. Puzder, A.J. Williamson, J.C. Grossman, G. Galli, Surface chemistry of silicon nanoclusters // Phys. Rev. Lett. 88(9), p. 097401-1-097401-4 (2002). 